\title{
Abordagens metodológicas da pesquisa em Place Branding no campo do Turismo: Analise das produções científicas (teses e dissertações) no Brasil
}

Methodological approaches of Place Branding research in the field of Tourism: Analysis of scientific productions (thesis and dissertations) in Brazil

Anderson Leonardo de Castro Seabra (leonardoseabra@ufrn.edu.br) Doutorando do Programa em Pós-Graduação em Turismo da UFRN, Natal, Brasil. Mestre em Estudos Urbanos e Regionais (DPP/UFRN), e Bacharel em Administração (UFRN) e em Comunicação Social (UFRN).

Lissa Valeria Fernandes Ferreira (lissaferreira.iadb@yahoo.es)

Doutora em Administração pela Universidade Federal do Rio Grande do Norte (UFRN), Natal, Brasil. Professora adjunta da UFRN. Membro permanente do Programa de Pós-Graduação em Turismo (PPGTUR) da UFRN.

Pesquisadora do Grupo de Estudos em Gestão do Turismo (GESTUR) da UFRN.

\section{RESUMO}

Este estudo analisa a produção científica das pesquisas em Place Branding no campo do Turismo no Brasil, a partir do levantamento de teses e dissertações, para identificar as suas principais características quanto a metodologia. Do exame de 41 trabalhos foi possivel conhecer e enquadrar as abordagens metodológicas adotadas pelos pesquisadores nesse específico campo. Entre os principais resultados: Identificada a hegemonia da postura epistêmica empírico-analítica dos estudos; o uso de métodos essencialmente positivistas; ampla recorrência de abordagens qualitativas. Conclui-se que as pesquisas em Place Branding no Brasil têm seguido uma agenda de pesquisa positivista, essencialmente empírica, e, pouco reflexiva. Espera-se que 
estimule a discussão sobre novas e distintas possibilidades bem como a extensão para outros estudos que ampliem a compreensão sobre seus modos de investigação.

Palavras-chave: Pesquisa, Metodologia, Place Branding, Turismo, Brasil

\section{ABSTRACT}

This study analyzes the field of research on Place Branding in Brazil, from the survey of published thesis and dissertations, to identify its main characteristics regarding the methodology. From the examination of 4 lacademic works it was possible to frame the methodological approaches adopted by the researchers in this specific field. Among the main results: Identified the hegemony of the empirical-analytic epistemic posture of the studies; the use of essentially positivist methods; dominance of qualitative approaches. It is concluded that research on Place Branding in the field of study of Tourism in Brazil has followed a positivist research agenda, essentially empirical, and not very reflective. It is expected to stimulate discussion about new and distinct possibilities as well as extension to further studies that broaden the understanding of their modes of inquiry.

Keywords: Research; Methodology, Place Branding, Tourism, Brazil

\section{INTRODUÇÃO}

O Branding se tornou uma atividade de marketing de alta prioridade nas últimas décadas, principalmente devido à percepção de que as marcas são um dos ativos intangíveis mais valiosos que as organizações possuem, serem fatores críticos de sucesso e que, estrategicamente, representam componente de vantagem competitiva (Keller, 1993; Keller \& Lehmann, 2006; Kotler \& Getner, 2002)

O fenômeno do turismo, por sua vez, atrai cada vez mais empresários e investimentos para um mercado disputado e de extrema competição entre 
lugares. É nesse cenário, que a adoção de ferramentas estratégicas, tais como o Branding se tornou recorrente, não somente na promoção de empresas de forma eficiente, mas também de destinos turísticos (nações, cidades e regiões) que desenvolvem marcas a procura de obter vantagem competitiva (Braun, 2012; Kavaratzis \& Ashworth 2005; Kotler \& Gertner, 2002; Ocke \& Ikeda, 2014).

De fato, organizações públicas e parapúblicas em todos os níveis local, regional, nacional, internacional - tem dedicado esforços e recursos significativos em estratégias de place branding, no intituito de construir marcas fortes e favoráveis para projeta-las com a intenção de influenciar a percepção do lugar em questão, torna-lo único e atraente para os gruposalvo desejados (Merrilees, Miller, \& Herington, 2012; Vuignier, 2017).

Em meio a esse contexto, o Place Branding emergiu rapidamente como um domínio de pesquisa dedicado à análise científica dessas práticas se tornando um dos tópicos proeminentes de estudo (Gertner, 2011; Mikulic, Miličević \& Krešić, 2016).

O avanço da pesquisa científica em qualquer campo de conhecimento também depende que os pesquisadores tenham consciência da importância dos métodos utilizados em seus estudos (Kovacs, Barbosa, Souza \& Mesquita, 2012).

Acompanhando a evolução das pesquisas nessa arena de estudos, diversos autores realizaram investigações importantes e apresentaram um panorama geral sobre os seus aspectos metodológicos, tais como Zencker (2011), Gertner (2011), Lucarelli e Berg (2011), Lucarelli e Brorström (2013), Chan e Marafa, (2013), Oguztimur e Akturan (2015), Vuignier (2017), Acharya e Rahman (2016).

Portanto, para se somar aos estudos antecessores, e, apresentar novas contribuições, o presente artigo tem como objetivo realizar um exercício de revisão contemporânea e concisa sobre as abordagens metodológicas, métodos e estratégias utilizadas na produção científica em place branding, 
no Brasil, em particular mediante analise criteriosa de teses e dissertações defendidas entre 2003 e 2018.

Deste modo, na presente investigação, se espera fornecer um quadro a respeito das abordagens e procedimentos adotados nas pesquisas de teses e dissertações que abordam o fenômeno do Place Branding no Brasil.

\section{SOBRE AS ABORDAGENS METODOLÓGICAS AO PROBLEMA DE PESQUISA: CARÁTER E FORMA.}

Enquadrar uma pesquisa científica pode resultar em tarefa complexa, se considerada a diversidade de abordagens e técnicas, bem como a profusão de autores, que apresentam diferentes formas de classificação e taxonomias, cada um com suas especificidades (Gil, 2009), e, critérios, que podem variar de acordo com o enfoque dado (Marconi \& Lakatos, 2010).

Essa dificuldade, podem levar os pesquisadores a um exaustivo trabalho de seleção daqueles que melhor esclareçam e qualifiquem os métodos empregados, como se pretende fazer a seguir, na seguinte sequência: Paradigma de pesquisa (Matriz Paradigmática), método de abordagem, natureza da abordagem ao problema, natureza do problema, caráter da pesquisa com base no objetivo e delineamento/estratégia da pesquisa.

Inicialmente, vale considerar as distinções quanto ao método e à metodologia. Método consiste no caminho para se chegar a determinado fim ou objetivo. Distintamente, a metodologia fornece os procedimentos e regras utilizadas por determinado método (Richardson, 1999). Em termos específicos, método científico são os procedimentos intelectuais e técnicos adotados para se atingir o conhecimento (Gil, 2009). São as atividades racionais e sistemáticas que possibilitam alcançar o objetivo de modo seguro e com maior economia (Marconi \& Lakatos, 2010). 
As questões ligadas às metodologias de pesquisa são inerentes às posturas epistemológicas adotadas pelos pesquisadores. Qualquer trabalho científico se embasa em determinada estrutura de pensamento que pode se apresentar com maior ou menor coerência interna a partir de um ponto de vista epistemológico (Gamboa, 2012).

Um pesquisador deve fazer uso de uma estrutura que norteie seu projeto de pesquisa desde a identificação da postura epistemológica que fundamenta a postura filosófica do pesquisador frente ao objeto de pesquisa, até os procedimentos de coleta e análise dos dados (Creswell, 2010).

A dimensão epistemológica relaciona-se ao conhecimento e como ele pode ser obtido. A postura epistemológica ou pressupostos filosóficos, representa a forma como o pesquisador aprende e o que aprende com o projeto. Na literatura, é possível encontrar variadas formas de classificação das posturas epistemológicas, ou pressupostos filosóficos, adotados por pesquisadores, que foram sintetizados e esquematizados por estudiosos do campo da epistemologia.

Gamboa (1995, 2012), elaborou um esquema de análise epistemológica, conhecido como matriz paradigmática, no qual são listados três grandes grupos de pesquisa científica: empírico-analíticas; fenomenológico-hermenêuticas; e crítico-dialéticas.

O círculo das matrizes epistêmicas, de Paes de Paula (2016) abre espaço para o diálogo entre teorias e metodologias em uma lógica subdivida em três matrizes: empírico-analítica, hermenêutica (interpretativista) e a crítica, orientadas pelos interesses técnico, prático e emancipatório, respectivamente (Paes de Paula, 2016)

A matriz empírico-analítica está alinhada com a filosofia positivista, a lógica formal e a orientação para o interesse técnico. Os estudos pertencentes a essa matriz geram conhecimento capaz de possibilitar a predição e o controle dos fatos sociais. Em nível técnico as pesquisas empírico-analíticas, 
apresentam em comum a utilização de técnicas de coleta, tratamento e análise de dados marcadamente quantitativas com uso de medidas e procedimentos estatísticos.

A matriz hermenêutica ou hermenêutica-fenomenológica alinha-se com a filosofia interpretativista, guiando-se para o interesse prático. Neste caso, o conhecimento gerado visa à compreensão social por meio da comunicação e da interpretação (Paes de Paula, 2016).

Finalmente, a matriz crítica-dialética está voltada para a transformação social, em conformidade com o uso da lógica dialética (Paes de Paula, 2016). Se configuram nos estudos sobre experiências, práticas pedagógicas, processos históricos, discussões filosóficas ou análises contextualizadas a partir de um prévio referencial teórico, e, privilegiam os estudos teóricos e a análise de documentos e textos (Gamboa, 1995).

Uma pesquisa está inserida em um paradigma de conhecimento, que pressupõe, de um lado, determinados tipos de "método" ou "bases lógicas", e por outro a afinidade deste com os procedimentos e vice-versa (Saccol, 2009). A esse respeito, podem ser subdivididos em métodos de Abordagem e Métodos de procedimentos (Andrade, 2009; Gil (2009; Marconi e Lakatos, 2010).

Método de abordagem trata dos processos mentais e das operações lógicas mais abstratas e sua relação com a realidade (Marconi \& Lakatos, 2010). Os principais métodos que fornecem as bases lógicas à investigação são: dedutivo, indutivo, hipotético-dedutivo, hermenêutico, dialético e fenomenológico.

Ao iniciar sua investigação o pesquisador, eventualmente, se depara com a situação da escolha da abordagem a ser adotada: qualitativa ou quantitativa, ou a possibilidade de uma combinação das duas (Andrade, 2002; Gil, 2009; Creswell, 2010). Em geral, a escolha é feita predominantemente com base em seu campo de formação, 
conhecimentos ou pressões, do que nas necessidades reais de seu estudo (Menéndez, 2009).

Ao definir uma pesquisa como qualitativa ou quantitativa está sendo feita referência à forma como são analisados os dados obtidos, que, por sua vez, são determinantes dos instrumento(s) de coleta de dados (Barbosa et al, 2004; Cooper \& Schindler, 2003).

A pesquisa qualitativa se dedica à compreensão dos significados dos eventos, sem a necessidade de apoiar-se em informações estatísticas e com maior oportunidade de manifestação para a subjetividade do pesquisador (Flick, 2009). É fundamentada na fenomenologia, tem passos singulares na análise dos dados, se vale de diferentes estratégias de investigação, e, geralmente utilizam técnicas não-quantitativas (Creswell, 2010). A pesquisa quantitativa, tem como base o paradigma positivista. A mensuração é o ponto central a ser buscado e os números são representativos de opiniões e conceitos. Por isso, é caracterizada pelo uso da quantificação, tanto na coleta, geralmente por questionários ou formulários, quanto no tratamento das informações, se valendo de técnicas estatísticas (Richardson, 1999).

Alternativamente, as duas abordagens podem coexistir. A pesquisa quanti-quali, como o próprio nome sugere, representa a conjugação das duas modalidades em um único estudo, de modo que tenha uma parte quantitativa ao mesmo tempo que seja possível fazer interpretações e especulações sobre as causas dos resultados (Creswell, 2010).

Cada tipo de pesquisa trata o problema de uma forma particular, que também dependerá do seu objetivo, podendo ser exploratória, descritiva ou explicativa (Andrade, 2009; Gil, 2009; Richardson, 1999).

A pesquisa exploratória aprofunda os conhecimentos das características de determinado fenômeno. Essencialmente, são investigações que buscam maior familiaridade com o problema, com vistas a torna-lo mais explícito, e, definir as questões ou hipóteses para uma investigação posterior (Gil, 2009; Richardson, 1999; Yin, 2005). As pesquisas 
descritivas objetivam à circunscrição das características de determinadas populações ou fenômenos, identificar a correlação entre variáveis, e, focam-se não somente na descoberta, mas também, análise dos fatos, descrevendo-os, classificando-os e interpretando-os (Richardson, 1999). Uma de suas características está na utilização de técnicas padronizadas de coleta de dados, tais como o questionário e a observação sistemática. Nos explicativos, o investigador estuda o problema a procura de informação que possa possibilitar o estabelecimento de relações de causa-efeito (Gil, 2009). A maioria das pesquisas explicativas utiliza o delineamento experimental, que possibilita a manipulação e o controle de variáveis, observa Andrade (2009). Essas pesquisas são na maioria das vezes uma continuação das pesquisas exploratórias e descritivas (Yin, 2005).

A opção pelas abordagens e a definição dos objetivos determina que tipos de dados serão coletados e, por conseguinte a estratégia de coleta (Cooper \& Schindler, 2003). O delineamento ou estratégia da pesquisa refere-se ao seu planejamento numa dimensão mais ampla, ou seja, nesse momento o investigador estabelece os meios técnicos da investigação, à maneira pela qual se conduz o estudo e se obtêm os dados para posterior análise (Creswell, 2010; Gil, 2009; Yin, 2005).

De acordo com a literatura, as principais estratégias consistem em: pesquisa bibliográfica, pesquisa documental, pesquisa experimental, pesquisa ex-post facto, levantamento (survey), estudo de caso, pesquisaação e pesquisa participante (Gil, 2009; Creswell, 2010).

Enquadrar uma pesquisa científica pode resultar em tarefa complexa, se considerada a diversidade de abordagens e técnicas, bem como a profusão de autores, que apresentam diferentes formas de classificação e taxonomias, cada um com suas especificidades (Gil, 2009), e, critérios, que podem variar de acordo com o enfoque dado (Marconi \& Lakatos, 2010). Essa dificuldade, podem levar os pesquisadores a um exaustivo trabalho de 
seleção daqueles que melhor esclareçam e qualifiquem os métodos empregados.

\section{TURISMO E PLACE BRANDING: APROXIMAÇÃO POR MEIO DAS ABORDAGENS DE PESQUISA}

Place Branding é um termo que refere-se ao desenvolvimento de marcas em diversos níveis geográficos, como regiões, cidades ou comunidades, geralmente com o objetivo de desencadear associações positivas e distinguir um local de outros. Parte da premissa que sugere que lugares, cidades, regiões ou países podem ser considerados marcas, desde que percebidos de tal maneira (Vela, Fernandez-Cavia \& Jimenez-Morales, 2013; Vela, 2013).

Invariavelmente, está relacionado à noção de que lugares competem com outros por pessoas, recursos e negócios (Ocke \& Ikeda, 2014; Kavaratzis \& Ashworth 2005; Kotler \& Gertner, 2015). Nesse contexto, os territórios, por meio de organizações públicas e para-públicas tem adotado o place branding como ferramenta estratégia de governança para projetar imagens e gerenciar percepções sobre lugares (Anholt, 2010; Braun, Eshuis, \& Klijn, 2014; Jarrat, Phelan, Wain \& Dale, 2018; Vuignier, 2017).

Com a intensificação da aplicação das práticas de place branding, o tema ganhou visibilidade e se tornou um dos principais tópicos entre acadêmicos e profissionais, que exploram o tema e geram dezenas de artigos e relatórios de pesquisas, sobretudo, nos últimos 20 anos, como pode ser visto na evolução quantitativa da produção (Imagem 1), período que marca o surgimento do Journal of Place Branding, que traz uma plataforma que serviu de fórum para impulsionar as pesquisas.

\section{Imagem 1 - A evolução quantitativa das pesquisas em Branding no campo do Turismo nas últimas três décadas}




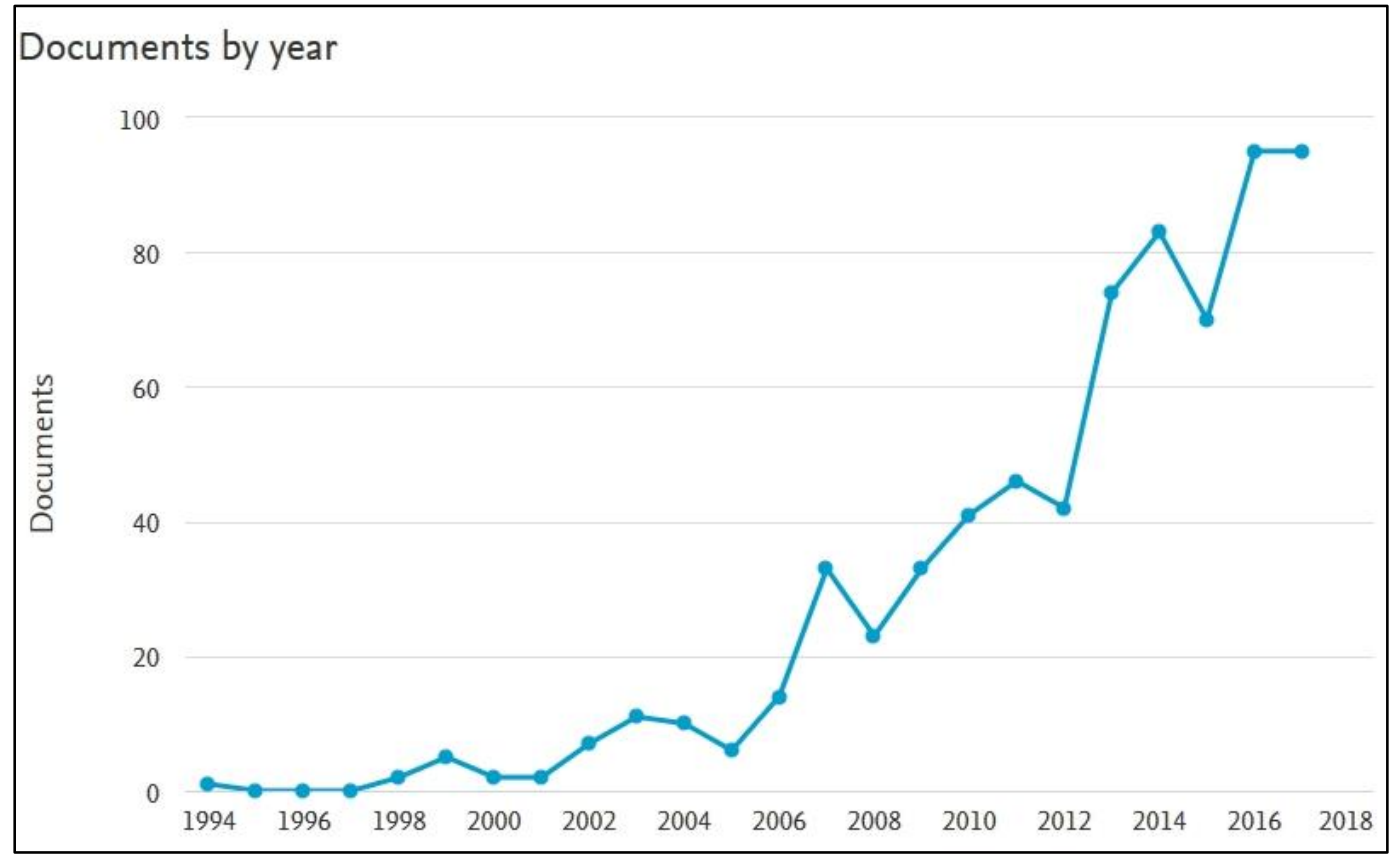

Fonte: Scopus (2018)

A literatura sobre place branding é cheia de idiossincrasias. Como um campo multidisciplinar relativamente novo que é amplamente baseado em evidências anedóticas de estudos de caso únicos (Lucarelli \& Berg, 2011) e influenciado pela abordagem prescritiva de consultores (Aronczyk, 2008; Boland, 2013) e outros profissionais (Niedomysl \& Jonasson, 2012), é fragmentado, carece de dados empíricos e requer maior rigor acadêmico.

O começo dos estudos em Place Branding pode ser matizado em duas correntes na literatura: uma concentrada nos estudos sobre país de origem e seus efeitos (Country-of-origin) (Kotler, Haider \& Rein, 1993; Kotler \& Gertner, 2002), enquanto a outra dedicada ao estudo sobre imagens de destinos turísticos (Gallarza, Saura \& Garcia, 2002).

As primeiras teorias sobre Place Branding no contexto do turismo tiveram notoriedade em 1998 quando o assunto foi tema do Annual Travel and Tourism and Research Association's Conference (Hanna \& Rowley, 2008). Ainda de acordo as autoras (2008), os estudos de Place Branding no turismo são também frutos da evolução do estudo sobre imagens de destino que se 
tornaram mais complexos e se aprofundaram em outras temáticas à medida que passaram a receber influências de outras áreas.

Seguindo a evolução do conceito de place branding, os acadêmicos realizaram investigações nas mais variadas áreas: Economia, Geografia, Turismo, Planejamento Urbano, Marketing, Comunicação, Patrimônio, Sociologia, Políticas Públicas, Arquitetura e Urbanismo, História, Design, Gestão, Psicologia, entre outros (Gertner, 2011; Lucarelli \& Brostrom, 2013; Vuignier, 2017).

Se tratando de um campo que estuda fenômenos e objetos tão complexos, como lugares, sua imagem e identidade, bem como formação da imagem de destinos turísticos, a preocupação de alguns pesquisadores se voltou para a reflexão sobre a metodologia utilizada de forma a satisfazer os objetivos pretendidos. Com efeito, surgem estudos que se propuseram a analisar a produção científica em place branding do ponto de vista metodológico, ou até mesmo como uma forma de inspeção dos métodos (Gertner, 2011; Lucarelli, 2012)

Gallarza et al. (2002) e Pike (2002) fizeram algumas observações sobre estudos de imagens de destinos que foram conduzidos ao longo das últimas décadas do século XX. Essas observações incluíram: (I) a falta de modelos e hipóteses testáveis na pesquisa de imagens de destino e (II) pequena quantidade de investigações aplicando métodos de pesquisa qualitativa nos estudos de comportamentos ou percepções do consumidor.

De acordo com Gallarza et al (2002), esses estudos de imagem de destino tratavam principalmente da avaliação e medição de imagens pelos consumidores e, portanto, técnicas multivariadas eram predominantemente aplicadas para abordar uma estrutura multidimensional de imagem de destino turístico.

Mais recente neste século, surgiram novas investigações que se debruçaram sobre as produções científicas em place branding e que puderam destacar as características metodológicas mais predominantes 
desse tópico de pesquisa: A influência derivada de numerosas disciplinas acadêmicas (Lucarelli \& Brorström, 2013), a primazia da abordagem qualitativa na maioria das áreas específicas (Acharya \& Rahman, 2015; Chan \& Marafa, 2013; Gertner, 2011; Lucarelli, 2012; Lucarelli \& Berg, 2011; Lucarelli \& Brorström, 2013, Vuignier, 2017; Zencker, 20111), a priorização de estudos de natureza exploratória e descritiva (Acharya \& Rahman, 2015; Chan \& Marafa, 2013; Vuignier, 2017;), a baixa participação de pesquisa empírica quantitativa (Gertner, 2011), a predominância da estratégia de Estudos de Caso único (Acharya \& Rahman, 2015; Chan \& Marafa, 2013; Lucarelli, 2012; Lucarelli \& Brorström, 2013), a falta de abordagens integradas de pesquisa, em raras combinações (Chan \& Marafa, 2013; Zenker, 2011).

No Turismo, há uma infinidade de procedimentos metodológicos e instrumentos que estão à disposição dos pesquisadores conforme a disciplina na qual o estudo é desenvolvido (Bispo, 2016) que interagem para produzir os conhecimentos e a compreensão dos fenômenos.

A multidimensionalidade do turismo permite sua análise a partir de diversas metodologias, a depender dos objetivos e do tipo de análise que se opta na investigação. Deste modo, cabe ao pesquisador escolher a abordagem que responda satisfatoriamente o propósito da pesquisa (Marujo, 2013).

Ainda que os estudos no turismo se desenvolvam com o aporte das mais variadas orientações teóricas e metodológicas, são observadas certas tendências ou preferências. Em levantamentos feitos no Brasil (Costa, Tito, Brumatti \& Alexandre, 2017; Eidt, 2004; Kovacs et al., 2012; Lage \& Milone, 2000; Sakata, 2002), foi possível identificar, nas produções de teses e dissertações, a dominância das pesquisas qualitativas, das investigações de caráter exploratório, e, ampla utilização das estratégias de estudo de caso e pesquisa documental.

Segundo Alves (2011), é comum privilegiar a abordagem funcionalista em detrimento de outras, como a dialética e crítica. A respeito da extensiva 
utilização da estratégia de estudo de caso, Marujo (2016) considera que seria em virtude de proporcionar melhor compreensão de certos fenômenos em comparação a outros.

No Turismo, há uma infinidade de procedimentos metodológicos e instrumentos que estão à disposição dos pesquisadores conforme a disciplina na qual o estudo é desenvolvido (Bispo, 2016) que interagem para produzir os conhecimentos e a compreensão do fenômeno.

Aplicar métodos e técnicas para estudar os fenômenos no campo do turismo é imprescindível, e, para isso o uso da metodologia torna-se essencial, pois ela é o modo de gerar conhecimento (Dencker, 2007). Sendo assim, faz sentido para todo pesquisador compreender os principais paradigmas de pesquisa, as abordagens, e, as tipologias associadas, da sua área de estudo, que orientam as escolhas que conferem forma a sua pesquisa. E, portanto, é valido discutir as possibilidades mais adequadas e eficientes de produção e difusão do conhecimento nestas áreas.

\section{PROCEDIMENTOS METODOLÓGICOS DO ESTUDO}

Constitui-se em pesquisa bibliográfica e pesquisa documental, se valendo de material que ainda não recebeu tratamento (Gil, 2009), apoiada pela análise de conteúdo, dado que algumas informações não constavam de forma explícita ou faziam menções as tipologias. Portanto, se vale da observação, do registro, da análise e da interpretação dos dados.

O universo da pesquisa é constituído de teses e dissertações selecionados mediante levantamento na base de dados da Biblioteca Digital de Teses e Dissertações (BDTD). Na presente pesquisa, para a identificação dos trabalhos pertinentes ao tema, se estabeleceu uma estratégia por meio da aplicação de filtros do próprio banco de dados.

Foi utilizada a opção "busca avançada", conforme, o grau do documento (tese ou dissertação), o idioma (português ou inglês), e as palavras "Brand", "Place Branding", "Marca", "Turismo", "Turístico", "Destino", 
contidas no título, resumo ou abstract, assunto ou palavras-chave. Bem como examinadas menções a essas terminologias na problemática, objetivos e área de concentração do estudo.

Deste modo, foram elencados 50 trabalhos, entre teses e dissertações publicadas no idioma português e 03 no idioma inglês, resultando em um total de 53. É importante ressaltar, que foi utilizada uma perspectiva histórica, isto é, não foi definido um recorte longitudinal, mas se considerou o intervalo temporal que abrange a base de dados.

As ocorrências foram submetidas a uma primeira coleta e análise de dados para verificar sua relevância dentro do contexto do estudo e o atendimento dos requisitos, compilados por meio de uso de planilha eletrônica.

Como resultado, a amostra ficou restrita a 41 teses e dissertações, defendidas entre 2003 e 2018, tabuladas em definitivo e que tiveram os seus procedimentos metodológicos analisados com base no roteiro préestabelecido. Julgou-se a amostra significativa para os fins da pesquisa, sem prejuízos potenciais a relevância dos dados obtidos ou ao rigor científico. Os dados gerais (perfil) como título, autoria, grau, ano de defesa, programa de pós-graduação constam no Apêndice I.

O conjunto de categorias de análise foi definido a priori com base na literatura específica sobre o tema. Os elementos estudados nesta pesquisa são apresentados na forma de constructos e variáveis (quadro 1), e, os autores utilizados são Andrade (2009), Dencker (2007), Gil (2009), Richardson (1999), Creswell, (2010) Marconi e Lakatos, (2010), Flick (2004), Gamboa (1995, 2012), Paes de Paula (2014, 2016), Severino (2007).

Importante fazer algumas observações: A classificação da pesquisa como abordagem quanti-quali considerou aquelas que combinaram ambas, em diferentes etapas da pesquisa ou pela combinação de métodos de coleta e/ou análise. Em itens como, objetivo da pesquisa, delineamento \estratégia de pesquisa e instrumentos de coleta de dados, 
em que se observou mais de uma forma, pela própria característica da pesquisa, foram registradas todas elas.

Deste modo, as produções científicas, constituídas por teses e dissertações, foram analisados levando em consideração as variáveis apresentadas. Em posse dos dados, foi possível descrever as características identificadas e realizar inferências sobre os procedimentos metodológicos adotados pelos pesquisadores, expostos na seção a seguir.

Quadro 01 - Conjunto de variáveis e unidades de análise da pesquisa

\begin{tabular}{|c|c|c|}
\hline Constructo & Variável & Variáveis específicas \\
\hline \multirow{5}{*}{$\begin{array}{l}\text { Abordagem } \\
\text { Metodológica }\end{array}$} & $\begin{array}{l}\text { Matriz-Paradigmática } \\
\text { Epistêmica }\end{array}$ & $\begin{array}{l}\text { Empírico-analíticas; } \\
\text { fenomenológico-hermenêuticas; e } \\
\text { crítico-dialéticas. }\end{array}$ \\
\hline & $\begin{array}{l}\text { Método de abordagem } \\
\text { (bases lógicas) }\end{array}$ & $\begin{array}{l}\text { Dedutivo, Indutivo, Hipotético- } \\
\text { Dedutivo, Fenomenológico, } \\
\text { Dialético, Histórico }\end{array}$ \\
\hline & Abordagem do & $\begin{array}{l}\text { Quantitativo, Qualitativo, Quanti- } \\
\text { Quali }\end{array}$ \\
\hline & Objetivo do estudo & Exploratório, descritivo, explicativo \\
\hline & $\begin{array}{l}\text { Delineamento } \\
\text { Estratégia de pesquisa }\end{array}$ & $\begin{array}{l}\text { Pesquisa bibliográfica, pesquisa } \\
\text { documental, } \\
\text { experimental, pesquisa ex-post } \\
\text { facto, levantamento (survey), } \\
\text { estudo de caso, pesquisa-ação e } \\
\text { pesquisa participante }\end{array}$ \\
\hline
\end{tabular}

Fonte: Elaboração própria (2018)

\section{DESCRIÇÃo E ANÁLISE dOS RESULTADOS}

Contemplam-se, nesta seção, os resultados encontrados após confrontar a abordagem metodológica adotada pelas teses e dissertações coletadas e o framework teórico-metodológico evidenciado nas seções anteriores, acompanhados pela análise do que foi observado e registrado. É também feita comparação com outros resultados encontrados em estudos anteriores que fizeram levantamentos a respeito do mesmo tópico de pesquisa. 
Abordagens metodológicas da pesquisa em Branding no campo do Turismo: Analise das produções científicas (teses e dissertações) no Brasil

Primeiramente, as teses e dissertações foram examinadas quanto as suas matrizes epistêmicas ou pressupostos filosóficos que embasaram os estudos (Tabela 1). Os resultados obtidos revelam predominância da Empírica-Analítica (30), seguida pela matriz Hermenêutico-Fenomenológica (10). A matriz crítico-dialético mostrou-se pouco expressiva, tendo guiado apenas um estudo. Nas tabelas 2, 3 e 4 as correspondentes dissertações e teses estão identificadas de acordo com as matrizes epistêmicas.

Tabela 1 - Classificação das pesquisas nas Matrizes Epistêmicas

\begin{tabular}{|l|l|l|}
\hline Matriz & \multicolumn{2}{l|}{ Contagem $\%$} \\
\hline Empírico-analítica & 30 & $73,1 \%$ \\
\hline Hermenêutico-fenomenológica & 10 & $24,3 \%$ \\
\hline Crítico-Dialética & 1 & $2,4 \%$ \\
\hline Total Geral & $\mathbf{4 1}$ & $100 \%$ \\
\hline
\end{tabular}

Fonte: Pesquisa, 2018

Não se pode deixar de considerar que essa é uma subárea do marketing, e, que, portanto, sujeita a tradição empírico-positivista deste campo (Alcañiz, Simó, Garcia \& Herrera, 2008; SCUSSELL, 2017). A literatura é enfática quanto ao reconhecimento da primazia dos paradigmas positivistas e lógico-empiristas nas pesquisas em Marketing no Brasil (Mello, 2006; Scussel, 2017).

Essa oposição do Marketing a outras abordagens não se refere à sua forma ou conteúdo, mas sim ao seu método (Boava \& Macedo, 2012). Contudo, tem se revelado insuficiente para responder aos questionamentos atuais, desse modo, sendo recomendada a busca por perspectivas alternativas (Saverbronn, Cerchiaro \& Ayrosa, 2012).

Tabela 2 - Trabalhos identificados com a matriz crítico-dialética

\begin{tabular}{|c|c|}
\hline & Título \\
\hline $\begin{array}{c}\text { A imagem do Estado do Piauí na perspectiva do } \\
\text { marketing de lugar }\end{array}$ & Tese \\
\hline Marca Bahia no turismo: uma análise sobre a & Dissertação \\
\hline
\end{tabular}




\begin{tabular}{|c|c|}
\hline $\begin{array}{c}\text { adoção de uma identidade territorial na construção } \\
\text { de uma marca -lugar }\end{array}$ & \\
\hline $\begin{array}{c}\text { Curta Brasília: a imagem da cidade no olhar do } \\
\text { cinema e sua relação com o turismo }\end{array}$ & Dissertação \\
\hline
\end{tabular}

Fonte: Pesquisa, 2018

Tabela 3 - Trabalhos identificados com a matriz Empírico-Analítica

\begin{tabular}{|c|c|}
\hline Título & Grau \\
\hline Personalidade de Marca em Meios de Hospedagem & Dissertaçãc \\
\hline $\begin{array}{l}\text { Processo de prospecção e indicação de informações } \\
\text { para orientar a criação de marcas gráficas turísticas de } \\
\text { cidade: estudo aplicado à cidade Rio de Janeiro. }\end{array}$ & Dissertaçãc \\
\hline $\begin{array}{c}\text { Identidade de Marca-País: Comunicação da Marca } \\
\text { Brasil nos Estados Unidos da América }\end{array}$ & Dissertaçãc \\
\hline $\begin{array}{c}\text { Elementos visuais identificadores da marca de lugar em } \\
\text { peças gráficas do setor turístico de Florianópolis }\end{array}$ & Dissertaçãc \\
\hline $\begin{array}{l}\text { Análise da imagem da marca-destino de Florianópolis e } \\
\text { sua influência na satisfação e lealdade do turista }\end{array}$ & Dissertaçãc \\
\hline $\begin{array}{c}\text { O reposicionamento de uma marca hoteleira no Brasil: } \\
\text { um estudo de caso sobre o Club Med. }\end{array}$ & Dissertaçãc \\
\hline $\begin{array}{c}\text { A formação do poder da marca turística do país: } \\
\text { experimentos sobre o efeito recíproco causado por } \\
\text { destinos turísticos }\end{array}$ & Tese \\
\hline Imagem país na perspectiva dos turistas: o caso do Peru & Dissertaçãc \\
\hline $\begin{array}{c}\text { Nation branding through mega-events and the impact } \\
\text { on tourism development in the host country: a study on } \\
\text { the } 2014 \text { FIFA World Cup in Brazil }\end{array}$ & Dissertaçãc \\
\hline $\begin{array}{c}\text { Percepção visual da hospitalidade em logotipos } \\
\text { hoteleiros. }\end{array}$ & Dissertaçãc \\
\hline $\begin{array}{c}\text { The Challenges of Repositioning an International Brand: a } \\
\text { case study on the hospitality industry }\end{array}$ & Dissertaçãc \\
\hline $\begin{array}{c}\text { O papel do website na transmissão da identidade de } \\
\text { marca de uma destinação turística: o caso do Portal } \\
\text { Vivendo Pernambuco }\end{array}$ & Dissertaçãc \\
\hline Medindo a imagem do destino turístico & Dissertaçãc \\
\hline $\begin{array}{c}\text { Análise da relação causal entre imagem de destinos, } \\
\text { qualidade, satisfação e fidelidade: um estudo de } \\
\text { acordo com a percepção do turista nacional no destino } \\
\text { turístico Natal }\end{array}$ & Dissertaçãc \\
\hline $\begin{array}{l}\text { Fotografias de viagens nas redes sociais: um estudo } \\
\text { sobre os efeitos da visualização de fotografias na } \\
\text { imagem do destino e na intenção futura de visita }\end{array}$ & Tese \\
\hline $\begin{array}{l}\text { O processo de construção da imagem turística do } \\
\text { amazonas na percepção dos turistas internacionais }\end{array}$ & Dissertaçãc \\
\hline A imagem turística de São Sebastião & Dissertaçãc \\
\hline $\begin{array}{c}\text { Cluster Criativo de Turismo, Sustentabilidade e } \\
\text { Identidade do Destino Apresentada em Website: um } \\
\text { estudo em Olinda, PE }\end{array}$ & Dissertaçãc \\
\hline $\begin{array}{c}\text { Imagem do contexto turístico do município de Pomerode } \\
\text { no estado de Santa Catarina }\end{array}$ & Dissertaçãc \\
\hline
\end{tabular}


Abordagens metodológicas da pesquisa em Branding no campo do Turismo: Analise das produções científicas (teses e dissertações) no Brasil

\begin{tabular}{|c|c|}
\hline A formação da imagem de destinações turísticas & Dissertação \\
na Web : o estudo do Portal visiteportodegalinhas.com & \\
\hline Branding de destinos turísticos: um estudo a partir do & "Saffron City Brand Criteria" \\
\hline
\end{tabular}

Fonte: Pesquisa, 2018

Tabela 4 - Trabalhos identificados com a matriz HermenêuticaFenomenológica

\begin{tabular}{|c|c|}
\hline Título & Grau \\
\hline Destination Branding: análise do destino Bahia & Dissertação \\
\hline $\begin{array}{c}\text { Design gráfico na construção da identidade visual da } \\
\text { marca turística em city branding }\end{array}$ & Dissertação \\
\hline $\begin{array}{c}\text { The stakeholders" involvement in the process of building and } \\
\text { maintaining a destination brand }\end{array}$ & Dissertação \\
\hline $\begin{array}{l}\text { COLOMBIA ES PASIÓN: Um estudo sobre gestão e resultados } \\
\text { de um projeto de construção de marca país }\end{array}$ & Dissertação \\
\hline $\begin{array}{c}\text { A construção da identidade de marca de Gramado-RS } \\
\text { como "destino turístico modelo }\end{array}$ & Dissertação \\
\hline $\begin{array}{c}\text { Lugares à venda: A construção de um processo visual a } \\
\text { partir das marcas-território }\end{array}$ & Dissertação \\
\hline Marca lugar : lições da Nova Zelândia & Dissertação \\
\hline $\begin{array}{c}\text { Diretrizes para a construção de um aplicativo para } \\
\text { smartphones com foco na geração de experiências em } \\
\text { branding territorial. }\end{array}$ & Dissertação \\
\hline $\begin{array}{c}\text { Diretrizes para a criação de marcas emocionais em } \\
\text { empreendimentos hoteleiros de hotelaria de charme: um } \\
\text { estudo multicaso dos filiados da Associação de Hotéis } \\
\text { Roteiros de Charme em Santa Catarina }\end{array}$ & Tese \\
\hline $\begin{array}{c}\text { A imagem do destino turístico, na percepção dos atores do } \\
\text { trade turístico: um estudo da cidade histórica de } \\
\text { Diamantina/MG }\end{array}$ & Dissertação \\
\hline $\begin{array}{l}\text { Responsabilidade social e imagem de destinos turísticos: } \\
\text { estudo comparativo dos websites do Brasil e da Holanda }\end{array}$ & Dissertação \\
\hline $\begin{array}{l}\text { A relevância da administração estratégica de imagem } \\
\text { associada ao marketing turístico para a aquisição de } \\
\text { destinos: um estudo da cidade de São Paulo/SP }\end{array}$ & Dissertação \\
\hline $\begin{array}{c}\text { A construção da imagem da cidade de Porto Alegre, pelo } \\
\text { olhar do turista }\end{array}$ & Dissertação \\
\hline $\begin{array}{l}\text { Reflexões sobre a imagem percebida pelos participantes } \\
\text { de eventos governamentais realizados em Brasília }\end{array}$ & Dissertação \\
\hline $\begin{array}{c}\text { Das práticas marítimas modernas à elaboração da imagem } \\
\text { turística de fortaleza/Ceará }\end{array}$ & Dissertação \\
\hline $\begin{array}{l}\text { Políticas públicas no turismo brasileiro - A cidade de São Paulo e } \\
\text { a construção de sua identidade turística }\end{array}$ & Tese \\
\hline $\begin{array}{l}\text { O local das marcas: um estudo sobre a relação das marcas e a } \\
\text { identidade local na cidade de Chapecó, SC }\end{array}$ & Dissertação \\
\hline
\end{tabular}


Em relação aos Métodos de abordagem, na análise das teses e dissertações, como demonstrado na tabela (5) foi averiguado equilíbrio entre os métodos indutivo, fenomenológico, dedutivo e hipotético-dedutivo.

Tabela 5 - Os métodos de abordagem utilizados nas pesquisas

\begin{tabular}{|l|c|c|}
\hline Método & 10 & $24,3 \%$ \\
\hline Indutivo & 11 & $26,8 \%$ \\
\hline Fenomenológico & 10 & $24,3 \%$ \\
\hline Dedutivo & 9 & $21,9 \%$ \\
\hline Hipotético-dedutivo & 1 & $2,7 \%$ \\
\hline Dialético & 41 & $100 \%$ \\
\hline Total Geral & & \\
\hline
\end{tabular}

Fonte: Elaborado pelo autor (2018)

A participação do método indutivo pode ser explicada pela alta incidência de estudos cujo objeto é um caso único (um destino turístico específico, as práticas organizacionais de determinada empresa, processos de construção de marca), em busca de constatações mais gerais no domínio do branding. Essa constatação talvez explique a opção pelo método indutivo. Igualmente, o método dedutivo foi empregado em estudos que analisaram casos em busca de identificar leis mais gerais, que se aplicasse nas práticas de branding de destinos, por exemplo.

método hipotético-dedutivo, que responde por quase um quarto dos trabalhos examinados, confirma a tradição positivista nos estudos em branding. Pertencem a esse grupo, investigações que executaram a correlação de variáveis, testaram hipóteses para confirmação de modelos, e, portanto, recorreram ao referido método.

Cada tipo de pesquisa trata o problema de uma forma particular, que também dependerá do seu objetivo, podendo ser exploratório, descritivo ou explicativo. Em relação as produções examinadas com base nesse critério, 
Abordagens metodológicas da pesquisa em Branding no campo do Turismo: Analise das produções científicas (teses e dissertações) no Brasil

63,4\% foram caracterizadas como exploratório, 34,1\% como exploratóriadescritivo, e, um único evento de pesquisa explicativa, pouco usual no Turismo, conforme exposto na tabela 6.

Tabela 6 - Classificação das pesquisas quanto seu objetivo

\begin{tabular}{|l|c|c|}
\hline Caráter $\backslash$ Finalidade & Contagem & $\%$ \\
\hline Exploratória & 26 & $63,4 \%$ \\
\hline Exploratória-Descritiva & 14 & $34,1 \%$ \\
\hline Explicativa & 1 & $2,4 \%$ \\
\hline Total Geral & 41 & $100 \%$ \\
\hline
\end{tabular}

Fonte: Elaborado pelo autor (2018)

A pesquisa exploratória tem sido a mais frequente, tendo em vista que também foram empregadas juntamente a estudos descritivos, em investigações com maior nível de profundidade e objetivos mais abrangentes. Esse resultado é semelhante ao encontrado em estudos anteriores acerca da produção de branding no turismo (Acharya \& Rahman, 2015; Chan \& Marafa, 2013; Vuignier, 2017).

As pesquisas exploratórias, assim como as descritivas, são habitualmente realizadas por pesquisadores sociais em áreas voltadas para a prática (GIL, 2009). Branding é uma área tipicamente influenciada por profissionais do mercado. Geralmente, a pesquisa exploratória consiste no primeiro passo para quem pretende investigar sobre um campo pouco estudado. Por isso, serve como ponto inicial para pesquisas futuras, ao permitir definir as questões ou hipóteses para uma investigação posterior (Yin, 2005) ou descoberta e o aprimoramento de ideias (Malhotra, 2004). Com isso, pode se ver a importância deste tipo de pesquisa para contribuir com outros trabalhos, bem como etapa antecedente a um estudo descritivo.

Branding no contexto do turismo é um tópico de estudo relativamente novo, e, as pesquisas no Brasil são recentes, a primeira dissertação data de 
2003. Essa pode ser uma das causas para explicar a quantidade de estudos exploratórios verificados entre as produções científicas examinadas, que inclui também as investigações que se propuseram a descrever os fenômenos ou identificar características dentro desse campo em que os pesquisadores ainda buscam familiaridade com os objetos de estudo e aprofundamento teórico.

As pesquisas descritivas objetivam identificar correlação entre variáveis e focam-se não somente na descoberta, mas também, análise dos fatos, descrevendo-os, classificando-os e interpretando-os (Lakatos \& Marconi, 2010). Nesse tipo de pesquisa, identificam-se primeiramente as variáveis específicas que possam ser importantes, para posteriormente explicar as complexas características de um problema (Richardson, 1999).

Portanto, é possível inferir que as características particulares desses tipos de pesquisa combinado ao estado da produção científica desse tópico (branding no turismo) em especial no Brasil, na época das investigações, em termos de avanço do conhecimento, são prováveis causas para o resultado encontrado.

A respeito das abordagens da pesquisa quanto sua natureza, como exposto na tabela 7, foi constatada supremacia das pesquisas qualitativas, totalizando 27 (66\%), seguidas pela conjunção com a abordagem quantitativa verificado em 8 trabalhos, e, por fim, as investigações puramente quantitativas, representando $12,3 \%$ do universo, total de 5 .

Tabela 7 - Classificação das pesquisas quanto a natureza da abordagem

\begin{tabular}{|l|c|c|}
\hline Abordagem & Contagem & $\%$ \\
\hline Qualitativa & 27 & $65,8 \%$ \\
\hline Quanti-Quali & 9 & $21,9 \%$ \\
\hline Quantitativa & 5 & $12,3 \%$ \\
\hline Total Geral & 41 & 100 \\
\hline
\end{tabular}

Fonte: Elaborado pelo autor (2018) 
Abordagens metodológicas da pesquisa em Branding no campo do Turismo: Analise das produções científicas (teses e dissertações) no Brasil

Esse resultado, corrobora com os encontrados em estudos anteriores, que revelaram primazia da abordagem qualitativa (Acharya \& Rahman, 2015; Chan \& Marafa, 2013; Gertner, 2011; Lucarelli, 2012; Lucarelli \& Berg, 2011; Lucarelli \& Brorström, 2013, Vuignier, 2017; Zencker, 2011). Em relação a abordagem quantitativa, sua baixa incidência em relação a qualitativa, se assemelha aos achados de Gertner (2011).

A utilização de abordagem mista vai de encontro as percepções de Zenker (2011) e Chan e Marafa (2013), nos estudos em Branding, como também de Marujo (2013), no turismo, sobre as possibilidades de uso integrado para elevar a qualidade dos dados, e, consequentemente dos resultados. Cada abordagem acrescenta um tipo de informação ao quadro da investigação, o que expande os limites das análises, argumenta Marujo (2013).

Essa união de perspectivas quantitativas e qualitativas, segundo Creswell (2010), pode ser um sinal de preocupação com o problema de pesquisa em detrimento do foco no método.

Para Oliveira (2015), essa combinação de métodos, também conhecida como triangulação metodológica, representa uma das formas mais completas de pesquisa empírica porque associa a profundidade das análises subjetivas com a força de grandes amostras. Nestes termos, a abordagem multimétodo pode ser vista como uma forma de valorizar o problema de pesquisa.

Tabela 8 - As estratégias de pesquisa empregadas

\begin{tabular}{l|c|c|}
\hline Delineamento\Estratégi & $\begin{array}{c}\text { Contage } \\
\text { a }\end{array}$ & m \\
\hline Estudo de Caso & 31 & 43,6 \\
& & $\%$ \\
\hline Pesquisa Documental & 19 & 26,7 \\
\hline
\end{tabular}




\begin{tabular}{|l|c|c|}
\hline & & $\%$ \\
\hline Pesquisa Bibliográfica & 10 & 24,3 \\
\hline Levantamento (Survey) & 10 & 24,3 \\
& & $\%$ \\
\hline Quase-Experimental & 2 & $4,8 \%$ \\
\hline ex post-facto & 1 & $2,4 \%$ \\
\hline Experimental & 1 & $2,4 \%$ \\
\hline Total Geral & 71 & \\
\hline
\end{tabular}

Fonte: Elaborado pelo autor (2018)

A respeito do delineamento ou estratégias de pesquisa, a tabela 5 apresenta as opções feitas pelos pesquisadores nas produções analisadas. Nota-se que quando somados os números das estratégias utilizadas, é obtida quantidade superior às pesquisas examinadas (41). Isso se deve a utilização conjugada de pelo menos duas estratégias em 16 das 41 pesquisas. Pesquisas mais profundas, amplas e complexas, como as quanti-quali, utilizaram até 04 delineamentos. O percentual da tabela 8 trata da representatividade da estratégia em relação as 41 pesquisas.

É flagrante a incidência do estudo de caso como primeira opção de delineamento. Foram 31 (76\%) trabalhos que utilizaram essa estratégia, frequentemente combinado com outro, preferencialmente a pesquisa documental, que por sua vez, responde pelo segundo maior volume, presente em 19 (27\%) investigações. A estratégia de levantamento (13\%) foi das menos utilizada em virtude da quantidade de pesquisas quantitativas.

As estratégias experimentais, pouco usuais nesses campos de estudo, somam quatro investigações, entre as quais o quase-experimento corresponde à metade. A diferença do quase-experimento para os demais tipos experimentais está na manipulação da variável independente, portanto não há aleatoriedade (Malhotra, 2006; Creswell, 2010). Essa estratégia sofre com as ameaças à validade interna, entretanto apresentam 
melhores resultados que os experimentos verdadeiros em relação à validade externa (Calado \& Montgomer, 2003).

A alta incidência de pesquisa documental pode ser atribuída a quantidade de estudos que analisaram materiais de comunicação ou estratégias de branding formalizadas em relatórios e documentos governamentais e de empresas, o que justificaria a opção pela estratégia.

Outra situação comum é a utilização dos dados para triangular com os oriundos de outras fontes com fins de análise e validade. A pesquisa bibliográfica se fez mais presente em estudos quantitativos, em que os pesquisadores recorreram as referências teóricas para construir hipóteses, triangular fontes, e, dar sustentação a construção de categorias de análise.

A preferência pelo Estudo de Caso (único), observada nas pesquisas analisadas, sobretudo, nas investigações a respeito dos destinos turísticos, corrobora com estudos anteriores (Acharya \& Rahman, 2015; Chan \& Marafa, 2013; Lucarelli \& Brorström, 2013, Vuignier, 2017; Zencker, 2011). Assim como também a combinação de estratégias qualitativas com as iminentemente quantitativas, como pesquisa documental e o survey (Chan \& Marafa, 2013; Zencker, 2011).

Para uma visão mais integrada, foram detalhadas as pesquisas de acordo com sua forma de abordar o problema e sua finalidade dentro de cada matriz (Tabela 9). Esses dados são considerados importantes para analisar a coerência do método com os objetivos e procedimentos adotados.

Porém, é importante observar que não existe uma "receita metodológica" que determine um caminho linear entre paradigma-métodoprocedimentos, mas apenas a prévia consideração de que há afinidades (Saccol, 2009; Cooper \& Schindler, 2003).

Tabela 9 - Classificação das pesquisas nas Matrizes Epistêmicas 


\begin{tabular}{|l|c|}
\hline Empírico-analítica & 30 \\
\hline Qualitativa & 14 \\
\hline Exploratório & 13 \\
\hline Exploratório-Descritivo & 1 \\
\hline Quanti-Quali & 9 \\
\hline Exploratório-Descritivo & 9 \\
\hline Quantitativa & 5 \\
\hline Exploratório-Descritivo & 4 \\
\hline Explicativo & 1 \\
\hline Qualitativa & 1 \\
\hline Exploratório & 1 \\
\hline Hermenêutico- & 10 \\
\hline fenomenológica & 10 \\
\hline Qualitativa & 10 \\
\hline Exploratório & 1 \\
\hline Crítico-dialética & 1 \\
\hline Qualitativo & 11 \\
\hline Exploratório & \\
\hline Total Geral & \\
\hline
\end{tabular}

Fonte: Elaborado pelo autor (2018)

As investigações classificadas na matriz empírico-analítica respondem por todas as pesquisas multimétodo, que mesclaram técnicas quantitativas e qualitativas. Em muitos casos, fizeram uso de uma etapa qualitativa para atingir parte dos objetivos do trabalho, dado que demonstra correspondência com a quantidade de estudos exploratórios-descritivos. Na mesma matriz, estão concentradas as mais diversas estratégias de pesquisa, e, os casos em que os pesquisadores recorreram a maior variedade em um mesmo estudo. Essa opção pode ser explicada pelo fato de terem sido pesquisas multimétodo, ou seja, que utilizaram abordagens quanti-quali, possuíam objetivos mais amplos e complexos, e, níveis de análise mais profundos. 
Concernente aos estudos enquadrados segundo a matriz hermenêutico-fenomenológica, os estudos exploratórios de abordagem qualitativa (10), são representativos de sua perspectiva que engendra a subjetividade, presente na exploração e interpretação dos significados, das causas e o impacto do objeto estudado, conforme exposto na literatura (Richardson, 1999; Gamboa, 2012; Paes de Paula, 2016).

O que se aprende a partir dos dados da tabela 9 é que há coerência e adequação entre posturas epistemológicas e formas de abordagem aos problemas, que fica ainda mais claro ao comparar com os objetivos das pesquisas. Portanto, na caracterização de pesquisas quanto a questões metodológicas, a identificação das posturas epistemológicas pode contribuir como forma de prever as abordagens e procedimentos que serão utilizados e vice-versa.

\section{CONSIDERAÇÕES FINAIS}

O place branding é um fenômeno complexo, que está associado a uma diversidade de enfoques conceituais, e, conjuga diferentes saberes e pesquisadores de formações distintas na sua compreensão.

A metodologia pode servir como instrumento de caracterização de uma pesquisa, imprimindo-lhe a forma mediante a qual se empregam métodos e técnicas que são adotados para a obtenção do conhecimento acerca do objeto de estudo. Sendo assim, a partir da perspectiva metodológica, é possível capturar um retrato das principais características de uma pesquisa e até do campo de estudos o qual faz parte.

Este trabalho teve como objetivo conhecer e enquadrar as principais características metodológicas na produção científica brasileira em place branding no campo do Turismo tomando como referência as informações levantadas em teses e dissertações defendidas em Programas de Pósgraduação Stricto Sensu pelo país. A discussão foi situada nas abordagens 
metodológicas, e, que permitiu revelar os traços marcantes desse tópico de pesquisa.

Nas produções científicas examinadas neste estudo, foi constatado um grau direcionamento para determinados métodos, abordagens e estratégias, que não pode ser ignorado, embora haja esforços para o uso conjugado.

Foi observado um quadro de pesquisas caracterizado pelo predomínio de métodos baseados na abordagem empírico-analítica, ou seja, influenciadas pela filosofia positivista. Assim também foi evidenciado o aporte recorrente abordagem qualitativa de pesquisas, e, de cunho exploratório, com algumas variações, tendo o Estudo de Caso e a Pesquisa Documental como suas principais estratégias.

A hegemonia das pesquisas qualitativas e exploratórias, pode significar que o campo de estudos de place branding no país ainda careça de amadurecimento, e, de bases teóricas mais sólidas. Algumas estratégias têm sido pouco ou nunca utilizadas, o que pode servir de argumento ao estímulo de pesquisas originais e inéditas neste campo.

Em relação a postura epistemológica ou matriz-epistêmica, que fundamenta os procedimentos da pesquisa, a sua hegemonia indica o cumprimento de uma agenda positivista, com espaço ainda restrito para a reflexividade e a crítica. Essa postura, supõe a predisposição para abordar os problemas com o intuito de encontrar soluções.

Em algumas investigações que utilizaram a estratégia do Estudo de Caso, nota-se que poucos seguiram o caminho metodológico (protocolo) definido por Yin (2007). Parece haver então uma confusão terminológica a esse respeito, quando usam o rótulo "estudo de caso" ainda que os procedimentos não tenham sido adotados. Sendo assim, pode-se caracterizar esses estudos como um cruzamento entre um estudo de caso completo e detalhado com uma visão geral do caso e uma análise de um elemento ou fenômeno específico em um contexto particular. 
Foi notado que, embora os diferentes métodos tenham sido combinados na análise de dados, as abordagens qualitativas e quantitativas, tem sido utilizadas isoladamente. Também foi observado que a maioria dos estudos qualitativos utilizaram técnicas não estruturadas ou semiestruturadas de coleta de dados, consideradas convenientes pelos pesquisadores. Assim, os resultados desses estudos não podem ser considerados conclusivos e generalizáveis.

Não há dúvidas quanto a importância da pesquisa científica para o desenvolvimento dos diferentes campos do conhecimento. No caso específico do place branding, ainda em amadurecimento, as investigações e sua continuidade servirão de base para a sua estruturação. Deste modo, a reflexão a respeito da metodologia, dos modos de como aprender e gerar conhecimento por meio das pesquisas na área são fundamentais para o seu progresso em termos quantitativos e qualitativos.

As áreas do conhecimento não estão limitadas a um conjunto próprio e rígido de métodos e técnicas. A ciência é dinâmica, logo, métodos podem ser aprimorados ou desenvolvidos novos. Deste modo, é ainda valido discutir as possibilidades mais adequadas e eficientes de produção e difusão do conhecimento em qualquer área.

A título de sugestão para trabalhos futuros, destaca-se a ampliação de estudos como este, que verifiquem as técnicas de coleta de dados, as técnicas de análise, e, as principais limitações encontradas pelos pesquisadores, bem como o aprofundamento a respeito das motivações dos pesquisadores e orientadores para definição de determinadas abordagens.

\section{REFERÊNCIAS}

Aronczyk, Melissa. (2008). 'Living the Brand': Nationality, Globality, and the Identity Strategies of Nation Branding Consultants. International Journal of Communication, 2, 25. 
Acharya, Alok, \& Rahman, Zillur. (2016). Place Place Branding research: a thematic review and future research agenda. International Review on Public and Nonprofit Marketing, 1-29.

Alcañiz, J. E. B., Simó, L. A., García, I. S., \& Herrera, A. A. (2008). Investigación internacional en marketing turístico: análisis de contenido sobre temas y metodologías. Revista de Turismo y Patrimonio Cultural, 6(3), pp. 391-398.

Alves, M. (2011). Reflexões sobre a pesquisa qualitativa aplicada ao turismo. Revista Turismo em Análise, 22 (3), 599-613

Bispo, M. de S. (2016). Tourism as practice. Annals of Tourism Research, v.61, 170-179.

Boava, D. L. T.; Macedo, F. M. F. (2012). Breves Considerações sobre a Epistemologia do Marketing. In: XV SEMEAD - SEMINÁRIOS EM ADMINISTRAÇÃO. Anais... São Paulo.

Braun, E. (2012). Putting city branding into practice. Journal of Brand Management, 19(4), 257e267.

Chan, Chung Shing \& Marafa, Lawal. (2013). A review of place Place Branding methodologies in the new millennium. Place Place Branding and Public Diplomacy. 9. 10.1057/pb.2013.17.

Cooper, Donald R. \& Schindler, Pamela S. (2003). Métodos de pesquisa em administração. 7 ed.São Paulo: Bookman,. ISBN: 85-363-0117-1

Creswell, J. W (2010). Projeto de pesquisa: Métodos qualitativo, quantitativo e misto ( $3^{a}$ ed., 296p.). Porto Alegre: Artmed.

Dencker, Ada de Freitas Maneti. (2007). Pesquisa em turismo: Planejamento, métodos etécnicas. São Paulo: Futura.

Eidt, K. (2004). Turismo em Análise: a produção do conhecimento na área do turismo. 2004. 186p. Dissertação de Mestrado em Turismo e Hotelaria, Universidade do Vale do Itajaí, Balneário Camboriú.

Flick, U. (2004). Uma introdução à pesquisa qualitativa. 2. ed. Porto Alegre: Bookman.

Gallarza, M.G., Saura, I.G. and García, H.C. (2002) Destination image: Towards a conceptual framework. Annals of Tourism Research 29(1): 56-78. 
Gamboa, Sílvio Sánchez. (1995) Tendências epistemológicas: dos tecnicismos e outros "ismos" aos paradigmas científicos. In: Santos Filho, José Camilo \& Gamboa, Sílvio Sánchez. Pesquisa educacional: quantidade-qualidade. São Paulo: Cortez.

(2012). Pesquisa em Educação: métodos e epistemologias.2. Ed. Chapecó: Argos.

Gertner, D. (2011). Unfolding and configuring two decades of research and publications on place marketing and place Place Branding. Place Place Branding and Public Diplomacy, 7(2), 91-106.

Gil, A. C. (2009). Como elaborar projetos de pesquisa. 4ed. São Paulo: Atlas.

Hanna S. \& Rowley J. (2008) An analysis of terminology use in place Place Branding, Place Place Branding and public diplomacy, 4 (1), p. 61-75.

Jennings, G. (2009). Tourism research. 2. ${ }^{a}$ Ed., John Wiley \& Sons Australia, Milton.

Kavaratzis, M. (2004). From City Marketing to City Place Branding: Towards a Theoretical Framework for Developing City Brands. Place Place Branding, 1, 58-73.

Kavaratzis, Mihalis \& Ashworth, G.J.. (2005). City branding: An effective assertion of identity or a transitory marketing trick? Tijdschrift voor Economische en Sociale Geografie. 96. 506-514. 10.1057/palgrave.pb.5990056.

Keller, K. L. (1993). Conceptualizing, measuring and managing customerbased brand equity. Journal of Marketing, 57(1), 1e22

Keller, K., \& Lehmann, D. (2006) Brands and Place Branding: research findings and future priorities. Marketing Science, 25 (6), 740 - 759

Kotler Philip, \& Dubois Bernard. (2004). Marketing management (11th ed.). London, Pearson Education.

Kotler, P . \& Gertner , D . ( 2002 ) Country as brand, product, and beyond: A place marketing and brand management perspective. Journal of Brand Management $9(4 / 5): 249-261$.

Kotler , P . , Haider , D . and Rein , I . ( 1993 ) There's no place like our place! The marketing of cities, regions, and nations. The Futurist 27 (6) : 14-21. 
Kovacs, M. H., Barbosa, M. L. A., Souza, A. G. \& Mesquita, A. E.P. (2012). Pesquisa em turismo: uma avaliação das metodologias empregadas nos artigos publicados nos anais no triênio do seminário anual da associação brasileira de pesquisa e pós-graduação em turismo - anptur. Revista Visão e Ação. 14 (1), 19-34.

Lage, Beatriz Helena Gela; Milone, Paulo César (Organizadores). (2000). Turismo: teoria e prática. São Paulo: Atlas.

Li, X., and Petrick, J. (2008). "Reexaming the Dimensionality of Brand Loyalty: A Case of theCruise Industry." Journal of Travel \& Tourism Marketing, 25(1), 68-85.

Lucarelli, A., \& Berg, P. (201 1). City Place Branding: a state-of-the-art review of the research domain. Journal of Place Management and Development, 4(1), 9-27.

Lucarelli, A., \& Brorström, S. (2013). Problematizing place Place Branding research: a meta-theoretical analysis of the literature. The Marketing Review, $13(1), 65-81$.

Lucarelli, A., Berg, P. (2011). City Place Branding: a state-of-the-art review on the research domain. Journal of Place management and development, 4(1), 9-27.

Malhotra, N. K. (2004). Pesquisa de marketing: uma orientação aplicada. Porto Alegre: Bookman.

Marconi, M. de A. \& Lakatos, E. M., (2010). Fundamentos de metodologia científica (5th ed.). São Paulo: Atlas.

Marujo, N. (2013). Sociologia do Turismo na Educação Superior em Portugal. Revista Turismo \& Sociedade, v.6, n.3, p.490-507.

(2016). O estudo de caso na pesquisa em turismo: Uma abordagem metodológica. Turismo: Estudos \& Práticas, 5 (1), 113-128

Mello, S. C. (2006). Comentários: o que é o conhecimento em marketing no Brasil, afinal?. Revista de Administração Contemporânea, v. 10, n. 2, p. 203212,

Merrilees, B., Miller, D. and Herington, C. (2012), "Multiple stakeholders and multiple city brand meanings", European Journal of Marketing, Vol. 46 No. 7/8, pp. 1032-1047 
Mikulić, J., Miličević, K., Krešić, D. (2016) The Relationship Between Brand Strength and Tourism Intensity: empirical evidence from the EU capital cities. International Journal of Culture, Tourism and Hospitality Research, 10(1), 14-23

Niedomysl, Thomas, \& Jonasson, Mikael. (2012). Towards a theory of place marketing. Journal of Place Management and Development, 5(3), 223-230.

Ocke, Marco Antonio de Moraes, \& Ikeda, Ana Akemi. (2014). Marketing de lugar: estado da arte e perspectivas futuras. Revista de Administração (São Paulo), 49(4), 671-683.

Oguztimur, S., Akturan, U. (2015) Synthesis of City Place Branding Literature (1988-2014) as a Research Domain. International Journal of Tourism Research

Oliveira F. L. (2015). Triangulação metodológica e abordagem multimétodo na pesquisa sociológica: vantagens e desafios. Ciências Sociais Unisinos, v. 51, n. 2, p. 133-143..

Oliveira, M. O. R., \& Luce, F. B. (2011). O valor da marca: conceitos, abordagens e estudos no Brasil. REAd. Revista Eletrônica de Administração, $17(2), 502-529$.

Paes de Paula, A. P. (2014). Para Além dos Paradigmas nos Estudos Organizacionais: O Círculo das Matrizes Epistemológicas. In: IV Colóquio Internacional de Epistemologia e Sociologia da ciência da administração. Anais... Florianópolis - SC, 2014. v. IV.

\section{(2016) Para além dos paradigmas nos Estudos} Organizacionais: o Círculo das Matrizes Epistêmicas. Cadernos EBAPE.BR, v. 14, p. 26-46, 2016

Paiva Neto, Maria Carolina Cavalcante; Ferreira, Lissa Valéria Fernandes. (2016) Estudos sobre Place Branding no turismo: uma pesquisa bibliométrica na base científica da ANPTUR, In: XIII Seminário da Associação Nacional de Pesquisa e Pós-Graduação em Turismo (ANPTUR), São Paulo.

Vuignier, Renaud, (2017), Place Place Branding \& place marketing 1976-2016: A multidisciplinary literature review, International Review on Public and Nonprofit Marketing, 14, (4), 447-473

Richardson, Roberto Jarry. (1999). Pesquisa social: métodos e técnicas. 3. ed. São Paulo: Atlas. 
Sauerbronn, J. F. R., Cerchiaro, I. B. \& Ayrosa, E. A. T. (2012). Uma discussão sobre métodos alternativos em pesquisa acadêmica em marketing. Gestão e Sociedade, v. 5, n. 12, p. 254-269.

Severino, A. J. (2007). Metodologia do trabalho científico. 23. ed. São Paulo: Cortez. tourism. Clevedon: Channel View Publications, pp.1-8.

Scussel, F. B. C.(2017). Poder, Paradigmas e Domínio na Pesquisa em Marketing no Brasil: Uma Análise da Produção Nacional da Disciplina a Partir das Matrizes Epistêmicas. Administração: Ensino e Pesquisa, 18(3), 518-557.

Vela, Jordi. (2013). Place branding: A conceptual and theoretical framework. Boletin de la Asociacion de Geografos Espanoles. 189-211+467.

Yin. R. K. (2005). Estudo de caso: planejamento e métodos. 3 ed., Porto Alegre: Bookman.

Zenker, S. (2011). How to Catch a City? The Concept and Measurement of Place Brands. Journal of Place Management and Development, 4(1), 40-52.

\section{CONTRIBUIÇÃO DE CADA AUTOR/CO-AUTOR NO ARTIGO}

\begin{tabular}{|c|c|}
\hline Autor 1 (1 autor): & $\begin{array}{r}\text { Concepção da pesquisa; revisão da } \\
\text { literatura; coleta de dados; análise de } \\
\text { dados; discussão }\end{array}$ \\
\hline Autor 2 (co-autor): & $\begin{array}{r}\text { Revisão da literatura; análise de dados; } \\
\text { discussão }\end{array}$ \\
\hline
\end{tabular}

\section{APÊNDICE I - Lista de Teses e dissertações}

\begin{tabular}{|c|c|c|c|c|}
\hline Título & Grau & Autor & Ano & Programa/Instituição \\
\hline $\begin{array}{l}\text { Imagem do contexto turístico do município de } \\
\text { Pomerode no estado de Santa Catarina }\end{array}$ & Dissertação & Susana & 2003 & UFSC/PPGA \\
\hline $\begin{array}{l}\text { O processo de construção da imagem turística do } \\
\text { amazonas na percepção dos turistas internacionais }\end{array}$ & Dissertação & \begin{tabular}{|lr} 
Silva, & Laura \\
Almeida & de \\
Calasans & \\
\end{tabular} & 2004 & UFMG/CEPEAD \\
\hline Destination Place Branding: análise do destino Bahia & Dissertação & \begin{tabular}{|ll} 
Branisso, & Diana \\
Pereira & \\
\end{tabular} & 2005 & FGV/EAESP \\
\hline Medindo a imagem do destino turístico & Dissertação & \begin{tabular}{|l|} 
Pérez-Nebra, \\
Amalia Raquel
\end{tabular} & 2005 & UNB/PPG-PSTO \\
\hline $\begin{array}{l}\text { Das práticas marítimas modernas à elaboração da } \\
\text { imagem turística de fortaleza/Ceará }\end{array}$ & Dissertação & $\begin{array}{l}\text { Aragão, } \\
\text { Raimundo } \\
\end{array}$ & 2005 & UFC/PRODEMA \\
\hline Marca lugar : lições da Nova Zelândia & Dissertação & $\begin{array}{l}\text { Santana, Adriana } \\
\text { Campelo }\end{array}$ & 2006 & UFBA/PPGA \\
\hline
\end{tabular}




\begin{tabular}{|c|c|c|c|c|}
\hline $\begin{array}{l}\text { Percepção visual da hospitalidade em logotipos } \\
\text { hoteleiros. }\end{array}$ & Dissertação & $\begin{array}{l}\text { Robazzi, } \\
\text { Alexandre Nunes } \\
\end{array}$ & 2006 & UAM/PPGH \\
\hline $\begin{array}{l}\text { Marca Bahia no turismo: uma análise sobre a adoção } \\
\text { de uma identidade territorial na construção de uma } \\
\text { marca -lugar }\end{array}$ & Dissertação & $\begin{array}{ll}\text { Lima, } & \text { Frederico } \\
\text { Burgos } & \end{array}$ & 2008 & UFBA/PPGA \\
\hline A formação da imagem de destinações turísticas & Dissertação & $\begin{array}{l}\text { Moura, Francisco } \\
\text { Tigre }\end{array}$ & 2008 & UFPE/PROPAD \\
\hline $\begin{array}{l}\text { Diretrizes para a criação de marcas emocionais em } \\
\text { empreendimentos hoteleiros de hotelaria de charme: } \\
\text { um estudo multicaso dos filiados da Associação de } \\
\text { Hotéis Roteiros de Charme em Santa Catarina }\end{array}$ & Tese & $\begin{array}{l}\text { Zambon, Maria } \\
\text { Cristina } \\
\text { Fleischmann } \\
\text { Alves } \\
\end{array}$ & 2009 & UFSC/EGR \\
\hline $\begin{array}{l}\text { Curta Brasília: a imagem da cidade no olhar do } \\
\text { cinema e sua relação com o turismo }\end{array}$ & Dissertação & $\begin{array}{l}\text { Albernaz, Patrícia } \\
\text { da Cunha }\end{array}$ & 2009 & UNB/CET \\
\hline $\begin{array}{l}\text { Políticas públicas no turismo brasileiro - A cidade de } \\
\text { São Paulo e a construção de sua identidade turística }\end{array}$ & Tese & $\begin{array}{l}\text { Carvalho, Caio } \\
\text { Luiz Cibella de } \\
\end{array}$ & 2009 & ECA/USP \\
\hline $\begin{array}{l}\text { The stakeholders" involvement in the process of } \\
\text { building and maintaining a destination brand }\end{array}$ & Dissertação & $\begin{array}{l}\text { Antonsen, Inger } \\
\text { Marie Nyvoll }\end{array}$ & 2010 & FGV/EBAPE \\
\hline $\begin{array}{l}\text { Lugares à venda: A construção de um processo visual } \\
\text { a partir das marcas-território }\end{array}$ & Dissertação & $\begin{array}{l}\text { Henriques, } \\
\text { Fernanda } \\
\end{array}$ & 2010 & PUC-SP \\
\hline $\begin{array}{l}\text { Elementos visuais identificadores da marca de lugar } \\
\text { em peças gráficas do setor turístico de Florianópolis }\end{array}$ & Dissertação & $\begin{array}{|lr|}\text { Silva, Natacha } \\
\text { Camila Pontes da } \\
\end{array}$ & 2010 & UFSC/EGR \\
\hline $\begin{array}{l}\text { O reposicionamento de uma marca hoteleira no } \\
\text { Brasil: um estudo de caso sobre o Club Med. }\end{array}$ & Dissertação & $\begin{array}{l}\text { Moyses, Jeferson } \\
\text { Munhoz }\end{array}$ & 2010 & UAM/PPGH \\
\hline $\begin{array}{l}\text { A imagem do destino turístico, na percepção dos } \\
\text { atores do trade turístico: um estudo da cidade } \\
\text { histórica de Diamantina/MG }\end{array}$ & Dissertação & $\begin{array}{l}\text { Machado, } \\
\text { Danielle } \\
\text { Fernandes Costa } \\
\end{array}$ & 2010 & UFMG/CEPEAD \\
\hline $\begin{array}{l}\text { Análise da relação causal entre imagem de destinos, } \\
\text { qualidade, satisfação e fidelidade: um estudo de } \\
\text { acordo com a percepção do turista nacional no } \\
\text { destino turístico Natal }\end{array}$ & Dissertação & $\begin{array}{l}\text { Chagas, Márcio } \\
\text { Marreiro das }\end{array}$ & 2010 & UFRN/PPGTUR \\
\hline $\begin{array}{l}\text { A relevância da administração estratégica de } \\
\text { imagem associada ao marketing turístico para a } \\
\text { aquisição de destinos: um estudo da cidade de São } \\
\text { Paulo/SP }\end{array}$ & Dissertação & $\begin{array}{l}\text { Silvério, Ana } \\
\text { Paula Maiochi }\end{array}$ & 2010 & PUC-SP \\
\hline A imagem turística de São Sebastião & Dissertação & $\begin{array}{l}\text { Santaella, Liliane } \\
\text { Azevedo }\end{array}$ & 2010 & UNITAU/MGDR \\
\hline $\begin{array}{l}\text { The Challenges of Repositioning an International } \\
\text { Brand: a case study on the hospitality industry }\end{array}$ & Dissertação & Rivet, Virginie & 2011 & FGV/EAESP \\
\hline $\begin{array}{l}\text { O papel do website na transmissão da identidade de } \\
\text { marca de uma destinação turística: o caso do Portal } \\
\text { Vivendo Pernambuco }\end{array}$ & Dissertação & $\begin{array}{l}\text { Motta Filho, } \\
\text { Mauricy Alves da }\end{array}$ & 2011 & UFPE/PROPAD \\
\hline $\begin{array}{l}\text { Identidade de Marca-País: Comunicação da Marca } \\
\text { Brasil nos Estados Unidos da América }\end{array}$ & Dissertação & Mariutti, F.G. & 2012 & PPGAO/FEA-RP/USP \\
\hline $\begin{array}{l}\text { Responsabilidade social e imagem de destinos } \\
\text { turísticos: estudo comparativo dos websites do Brasil e } \\
\text { da Holanda }\end{array}$ & Dissertação & $\begin{array}{l}\text { Sales, } \quad \text { Rômulo } \\
\text { Quaresma }\end{array}$ & 2012 & UFPE/PROPAD \\
\hline $\begin{array}{l}\text { Design gráfico na construção da identidade visual da } \\
\text { marca turística em city Place Branding }\end{array}$ & Dissertação & $\begin{array}{ll}\text { Cardoso, } & \text { Helder } \\
\text { Antonio } & \text { Teixeira } \\
\text { Gomes } & \\
\end{array}$ & 2013 & UFSC/EGR \\
\hline $\begin{array}{l}\text { COLOMBIA ES PASIÓN: Um estudo sobre gestão e } \\
\text { resultados de um projeto de construção de marca } \\
\text { país }\end{array}$ & Dissertação & $\begin{array}{l}\text { Herminio, Michel } \\
\text { Candeloro }\end{array}$ & 2013 & ESPM \\
\hline $\begin{array}{l}\text { Processo de prospecção e indicação de informações } \\
\text { para orientar a criação de marcas gráficas turísticas } \\
\text { de cidade: estudo aplicado à cidade Rio de Janeiro. }\end{array}$ & Dissertação & $\begin{array}{l}\text { Napoleão, } \\
\text { Eduardo }\end{array}$ & 2014 & UFSC/EGR \\
\hline $\begin{array}{l}\text { Análise da imagem da marca-destino de Florianópolis } \\
\text { e sua influência na satisfação e lealdade do turista }\end{array}$ & Dissertação & $\begin{array}{l}\text { Zampieri, } \\
\text { Gabriela Mota }\end{array}$ & 2014 & UDESC/PPGA \\
\hline
\end{tabular}




\begin{tabular}{|c|c|c|c|c|}
\hline $\begin{array}{l}\text { Diretrizes para a construção de um aplicativo para } \\
\text { smartphones com foco na geração de experiências } \\
\text { em Place Branding territorial. }\end{array}$ & Dissertação & $\begin{array}{l}\text { Feijó, } \quad \text { Valéria } \\
\text { Casaroto }\end{array}$ & 2014 & UFSC/EGR \\
\hline $\begin{array}{l}\text { Cluster Criativo de Turismo, Sustentabilidade e } \\
\text { Identidade do Destino Apresentada em Website: um } \\
\text { estudo em Olinda, PE }\end{array}$ & Dissertação & $\begin{array}{l}\text { Crêspo, } \quad \text { Paula } \\
\text { Marin }\end{array}$ & 2014 & UFPE/PROPAD \\
\hline $\begin{array}{l}\text { A construção da identidade de marca de Gramado- } \\
\text { RS como "destino turístico modelo" }\end{array}$ & Dissertação & $\begin{array}{l}\text { Azambuja, } \\
\text { Vanessa Acosta } \\
\text { de }\end{array}$ & 2015 & UCS/PPGTUR \\
\hline $\begin{array}{l}\text { Fotografias de viagens nas redes sociais: um estudo } \\
\text { sobre os efeitos da visualização de fotografias na } \\
\text { imagem do destino e na intenção futura de visita }\end{array}$ & Tese & $\begin{array}{l}\text { Machado, } \\
\text { Danielle } \\
\text { Fernandes Costa }\end{array}$ & 2015 & UFRGS/PPGA \\
\hline $\begin{array}{l}\text { A formação do poder da marca turística do país: } \\
\text { experimentos sobre o efeito recíproco causado por } \\
\text { destinos turísticos }\end{array}$ & Tese & $\begin{array}{lr}\text { Santos, } & \text { Glauber } \\
\text { Eduardo } & \text { de } \\
\text { Oliveira } & \\
\end{array}$ & 2016 & PPAGO/FEA-RP/USP \\
\hline $\begin{array}{l}\text { Imagem país na perspectiva dos turistas: o caso do } \\
\text { Peru }\end{array}$ & Dissertação & $\begin{array}{l}\text { Ortiz, Victor Jesus } \\
\text { Escobedo. }\end{array}$ & 2016 & FGV/EAESP \\
\hline $\begin{array}{l}\text { Nation Place Branding through mega-events and the } \\
\text { impact on tourism development in the host country: a } \\
\text { study on the } 2014 \text { FIFA World Cup in Brazil }\end{array}$ & Dissertação & $\begin{array}{l}\text { Sörensen, } \\
\text { Mascha }\end{array}$ & 2016 & FGV/EBAPE \\
\hline Personalidade de Marca em Meios de Hospedagem & Dissertação & \begin{tabular}{|l|} 
Paiva \\
Aureo \\
\end{tabular} & 2017 & UFRN/PPGTUR \\
\hline $\begin{array}{l}\text { A imagem do Estado do Piauí na perspectiva do } \\
\text { marketing delugar }\end{array}$ & Tese & $\begin{array}{ll}\text { Lima, Maria } & \text { de } \\
\text { Fátima } & \text { de } \\
\text { Oliveira } & \\
\end{array}$ & 2017 & PUC-SP \\
\hline $\begin{array}{l}\text { A construção da imagem da cidade de Porto Alegre, } \\
\text { pelo olhar do turista }\end{array}$ & Dissertação & \begin{tabular}{|ll} 
Pujol, & Vinicius \\
Barbosa & \\
\end{tabular} & 2017 & UFRGS/PROPUR \\
\hline $\begin{array}{l}\text { Reflexões sobre a imagem percebida pelos } \\
\text { participantes de eventos governamentais realizados } \\
\text { em Brasília }\end{array}$ & Dissertação & $\begin{array}{l}\text { Oliveira, Adriana } \\
\text { Lemos de }\end{array}$ & 2017 & UNB/CET \\
\hline $\begin{array}{l}\text { O local das marcas: um estudo sobre a relação das } \\
\text { marcas e a identidade local na cidade de Chapecó, } \\
\text { SC }\end{array}$ & Dissertação & $\begin{array}{l}\text { Frandoloso, Pablo } \\
\text { Eduardo }\end{array}$ & 2017 & UFSC/PROPG \\
\hline $\begin{array}{l}\text { Branding de destinos turísticos: um estudo a partir do } \\
\text { "Saffron City Brand Criteria" }\end{array}$ & Dissertação & $\begin{array}{l}\text { Dias, Maria } \\
\text { Carolina } \\
\text { Cavalcante } \\
\end{array}$ & 2018 & UFRN/PPGTUR \\
\hline
\end{tabular}

